American Journal of Economics and Business Administration 3 (1): 132-138, 2011

ISSN 1945-5488

(C) 2010 Science Publications

\title{
Development of Interactive Courseware for Learning Basic Computer System Components
}

\author{
${ }^{1}$ Ida Aryanie Bahrudin, ${ }^{1}$ Muziah Muhammad, ${ }^{1}$ Mohd Izzaddin Abu Nawawi, \\ ${ }^{2}$ Isma Najwa Saharudin, ${ }^{3}$ Haniza Mohd Din, ${ }^{4}$ Mohd Azuan Ali and ${ }^{5}$ Mohd Ezree Abdullah \\ ${ }^{1}$ Computer System and Support Programme, \\ ${ }^{2}$ General Studies Unit, \\ ${ }^{3}$ Creative Multimedia (Advertising) Programme, \\ ${ }^{4}$ Business Accounting Programme, \\ Engineering and Skill Department \\ ${ }^{5}$ Civil and Environmental Engineering Faculty \\ ${ }^{1,2,3,4}$ Kolej Komuniti Jasin, 77300 Merlimau, Melaka, Malaysia \\ ${ }^{5}$ University Tun Hussein Onn, Malaysia
}

\begin{abstract}
A computer assisted learning approach was developed to enhance course material for students to learn about computer components, through the use of multimedia courseware. Recent advances in software authoring packages have made the production of CD-ROMs an efficient and effective educational strategy. Problem statement: This study reports on the development an evaluation of this courseware related to the learning basic computer system components through the use of courseware (iC-COM). The purpose of the study was to evaluate a courseware for learning basic computer system components. The basic components of iC-COM included an interface, graphics, sound effects, narration and video. Approach: The iC-COM was developed based on the ADDIE instructional system design model. The research instrument was the courseware evaluation in the form of questionnaire that consisted of various attributes included content, interactivity, navigation and screen design which distributed to 50 computer system and support programme students of Kolej Komuniti Jasin. Results: Based on the results, it was shown that the analysis results of each questionnaire item mean ranged from 3.5 to 3.8. Conclusion/Recommendations: For future enhancement, it is recommended that $\mathrm{iC}-\mathrm{COM}$ will be integrated into web-based platform so it can be accessed easily anywhere.
\end{abstract}

Key words: Interactive courseware, CD-ROM, computer system, enhance course, educational strategy

\section{INTRODUCTION}

There are many types of Teaching and Learning ( $\mathrm{T}$ and $\mathrm{L}$ ) method to be delivered in classroom. Although the conventional styles can be applied in classrooms, the alternative $\mathrm{T}$ and $\mathrm{L}$ style can help in improving students' knowledge and skills. Based on Helm-Stevens et al. (2009) a group work activities gives the student an opportunity to apply the information and take away something from the class though the skills can be taught in a class.

ICT otherwise known as Information and Communication Technology is widely spreading around the world as integral parts not only of teaching but in other aspects of human life as well. According to
Mudiarasan et al. (2008), technological breakthroughs, especially in ICT have brought unprecedented benefits to economies worldwide. Furthermore, the influence of information technology on social practices has mainly been to the effect of making information about them more accessible (Mahmoud, 2008). In the context of learning, ICT may be referred to as a necessary tool for students who desire further learning. This is also supported by Mohamed and Bakar (2008) that stated computer technology as an important integral tool in teaching field where the use of computer technology is said to benefit both students and teachers. Its usage alters the traditional roles of teachers in the classroom.

The widespread use of ICT tools in T and L has indirectly changed the way the learners interact with the

Corresponding Author: Ida Aryanie Bahrudin, Computer System and Support Programme, Kolej Komuniti Jasin, 77300 Merlimau, Melaka, Malaysia 
content. In the conventional way, the content is delivered verbally to the students, at the same time providing full human touch. According to Delombaerde (2001), multimedia software, whether distributed via CD-ROM or the internet, provides instructors with the possibility of enhancing or replacing their traditional education methods through multimedia demonstration and simulation.

An example of application of ICT in T and L is interactive courseware. The idea to develop an interactive courseware for basic computer system course to students is just an alternative on how the information source can be spread to the students interactively using the computers. According to Inglis et al. (2002), interactive courseware is generally understood to be a form of multimedia in which the presentation carried out in the digital form and interaction between the user and the presentation is supported.

The objective of the research was to have students' evaluation of the courseware of the strength and weaknesses of its instructional design.

Literature review: Computing and communication technology continue to make an ever-increasing impact on all aspects of cognition, education and training, from primary to tertiary and in the growing open and distance learning environment.

By using interactive courseware, the concept of Computer Assisted Learning (CAL) is applied. CAL was described in terms of the kind of information flowing between the students and his learning environment, mediated by the computers. Computer and their associated software present great opportunities for motivating students, encouraging independent learning and for improving the quality of educational programs (Westwood, 2008).

The courseware was developed as the reasons to include text, slides, videos and photoclip, to include computer simulation model, to maintain the logic and sequence of the existing course structure (Delombaerde et al., 2001).

Interactive multimedia weaves five basic types of media into the learning environment: Text, video, sound, graphics and animation. Since the mode of learning is interactive and not linear, a student or teacher can choose what to investigate next. For example, one does not start on the first page of a linear document and read to the end. According to Vaughan (2006), multimedia elements will provoke radical changes in teaching process during the coming decades, particularly as smart students discover that can go beyond the limits of traditional teaching methods.

\section{MATERIALS AND METHODS}

The most widely used methodology for developing new training programs is called Instructional Systems Design (ISD). It is also known as Instructional Systems Design and Development (ISDD). The ADDIE model or some derivative of it provides designers with the necessary structure for designing any curriculum, regardless of the instructional methods employed (Hodell, 2006). There are more than 100 different ISD models, but almost all are based on the generic “ADDIE" model, which stands for Analysis, Design, Development, Implementation and Evaluation, as illustrated in the Fig. 1.

Analysis: During analysis, the designer identifies the learning problem, the goals and objectives, the audience's needs, existing knowledge and any other relevant characteristics. According to Lynch and Roecker (2007), some of the activities in this phase are clarify objectives, agree to the scope, investigate constrains, determine the user and estimate the cost.

Several software packages were used in the courseware authoring process such as word processor, multimedia tools and voice recording software. This software was then used to implement the courseware material shown in Fig. 2.

The followings are the software packages that were used in iC-COM authoring process:

- $\quad$ Adobe Photoshop CS3

- Swish Max 3

- $\quad$ Sound Forge 9.0

- Windows movie maker

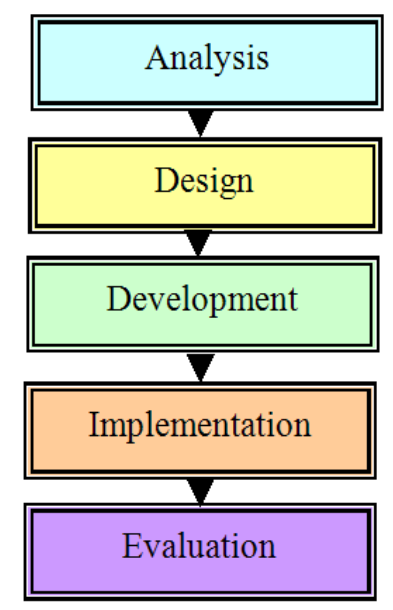

Fig. 1: Work flow based on ADDIE model 


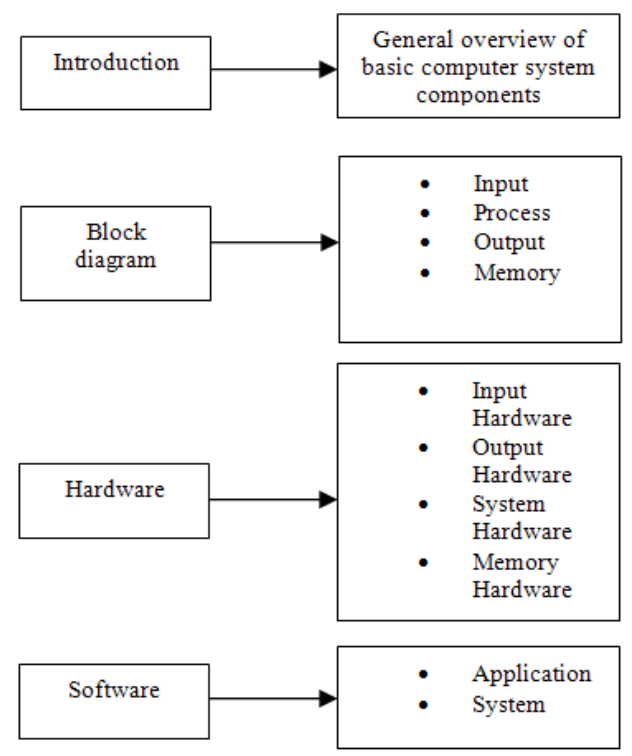

Fig. 2: Courseware material

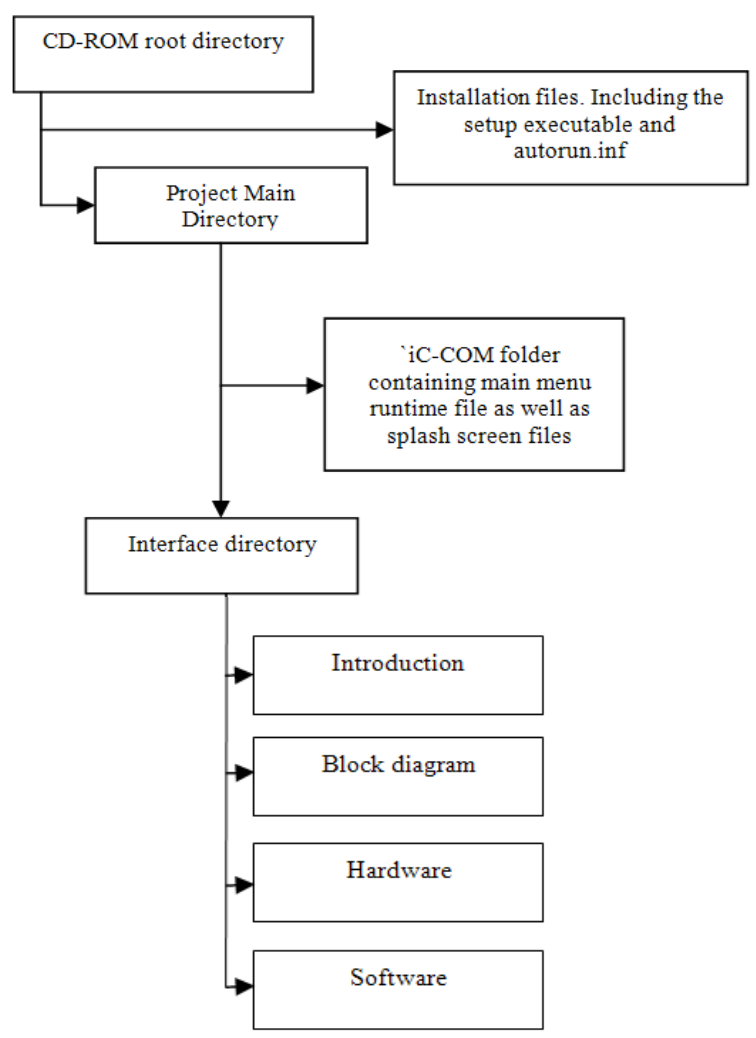

Fig. 3: IC-COM structure

Design: The design phase involves the complete design of the learning solution. It will address the training methodology, whether training will be administered online, detailed storyboards illustrating the training program and courseware content. During this phase, the following points are taken into account:

- The most appropriate media is selected by examining the kinds of skills required to achieve the goal

- The learning objectives are written and the modules are designed with its corresponding lessons

- Course content is designed specifically for use with an interactive, electronic medium in the case of online learning as shown in Fig. 3

- The appropriate interactions were determined. They should be creative, innovative and encourage learners to explore further

- Plan activities that allow for student group study to help construct a supportive social environment

Since the courseware CD-ROM contains information executed by the courseware itself, the directory structure and file locations were made to aid in the development process. Run-time file mapping consequently matched the directory structure. Installation file is located in the root directory of the CD-ROM for primarily for easy user access (Fig. 3). The setup.exe file is the only executable file located in the CD-ROM.

Development: This phase concerns with the actual production of the design specifications. It also involves creating or obtaining any media mentioned in the design of the courseware. During the development phase, all audio, video and text are collected, prepared or created (Belanger and Dianne, 2000). This phase sees the creation of storyboards, graphics and programming involved in the development. It involves the following considerations:

- Designing according to storyboard specifications

- Programming according to storyboard specifications

In this phase, the conventional course material was reviewed and transform into the flow chart form (Fig. 4). The course material was converted into digital format and also the hyperlinks between modules were created. From the flow chart, the program was developed with working modules and main hyperlinks between each sub-menu. The visual layout was then created along with the text and graphics inserted. The program animation was next rendered before the package media elements as well as program was developed. The last stage was performing BETA testing in classroom. 
Am. J. of Economics and Business Administration 3 (1): 132-138, 2011

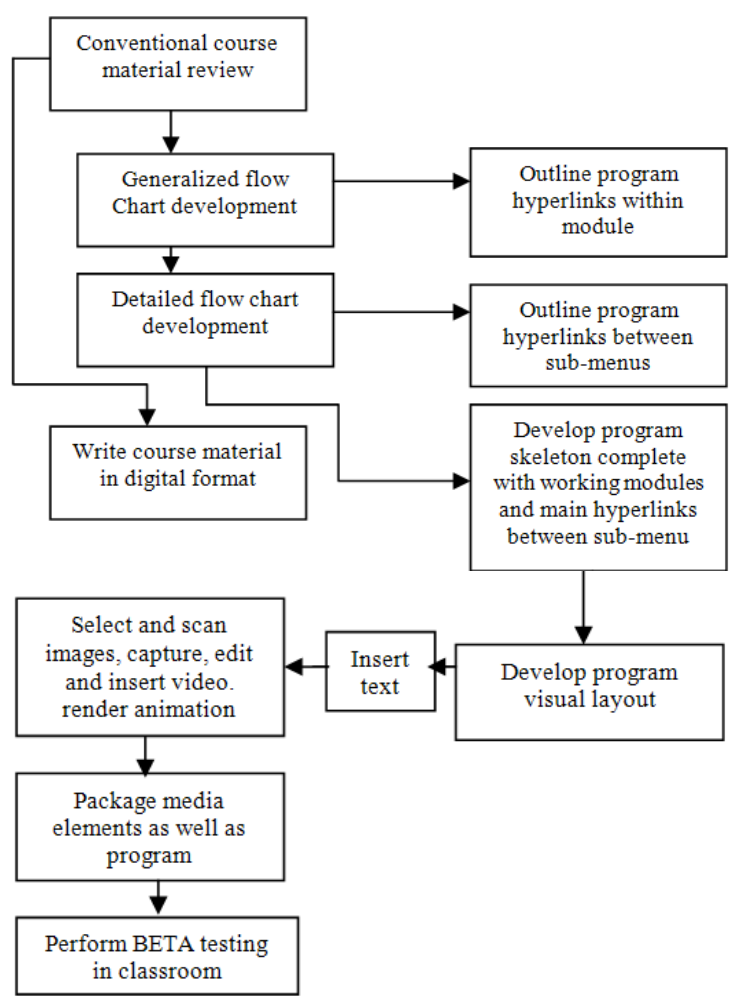

Fig. 4: Development scheme

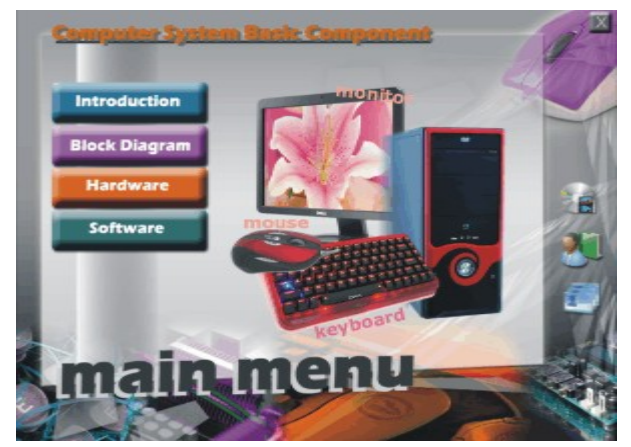

Fig. 5: Main menu of iC-COM

Implementation: This is the phase where the iC-COM is actually administered to the target audience. The delivery environment should be prepared for implementation of iC-COM.

Evaluation: This is the phase which decides whether iC-COM is effective and satisfies the objectives.

This phase considers feedback from learners. Evaluation had take place at the end stage of the project.

iC-COM: The main menu of iC-COM consists of 4 sub-menus such as Introduction, Block Diagram, Hardware and Software as shown in Fig. 5.

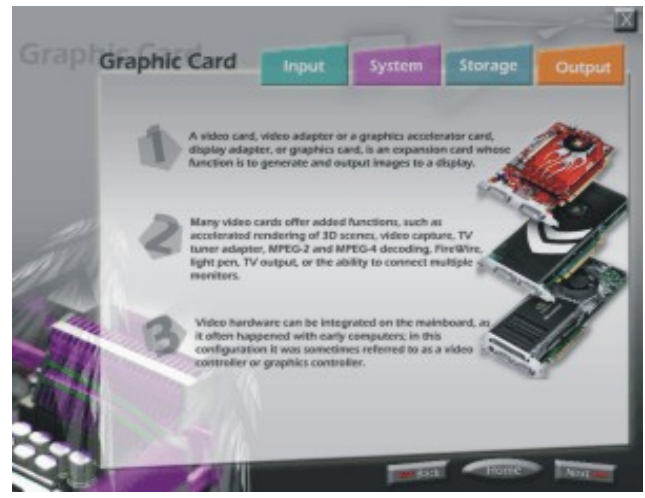

Fig. 6: Screen shot of text elements used in iC-COM

Interactive multimedia weaves five basic types of media into the learning environment: Text, video, sound, graphics and animation. Since the mode of learning is interactive and not linear, a student or teacher can choose what to investigate next.

Therefore iC-COM was designed to include all the elements. Out of all of the elements, text has the most impact on the quality of the multimedia interaction. Generally, text provides the important information. Text acts as the keystone tying all of the other media elements together. It is well written text that makes a multimedia communication wonderful. Figure 6 shows the screen shot of iC-COM that provide text element. The second elements in multimedia are graphics. Graphics provide the most creative possibilities for a learning session (Fig. 7). They can be photographs, drawings, graphs from a spreadsheet, pictures from CDROM, or something pulled from the Internet. The reason for this is that images make use of a massive range of cortical skills: Colour, form, line, dimension, texture, visual rhythm and especially imagination.

Animation is used to show changes in state over time, or to present information slowly to students so they have time to assimilate it in smaller chunks. Animations, when combined with user input, enable students to view different versions of change over time depending on different variables. Animations are primarily used to demonstrate an idea or illustrate a concept. Figure 8 shows example of animations to illustrate how the projector beam produce image on screen.

The other elements is video. Video can stimulate interest if it is relevant to the rest of the information on the page and is not 'overdone'. Video can be used to give examples of phenomena or issues referred to in the text.

For example, video to demonstrate how to assemble network card (Fig. 9). Along with the video and all the animation in $\mathrm{iC}-\mathrm{COM}$, is the audio to improve student's understanding. 
Am. J. of Economics and Business Administration 3 (1): 132-138, 2011

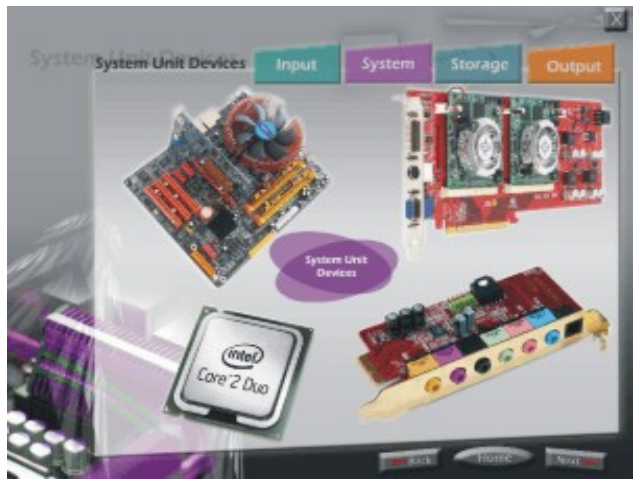

Fig. 7: The use of graphics elements in iC-COM

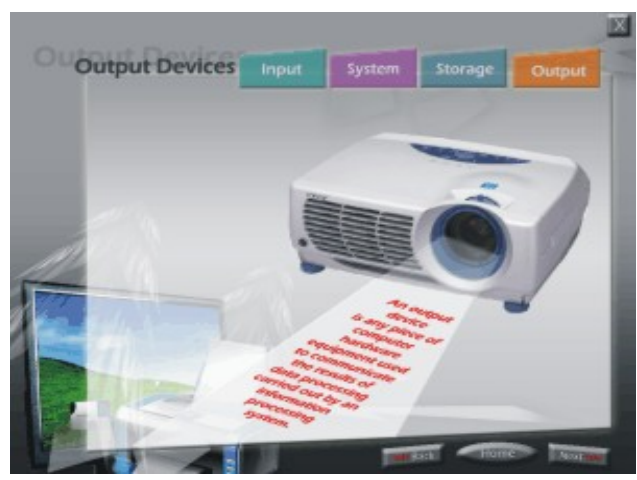

Fig. 8: Animations in iC-COM

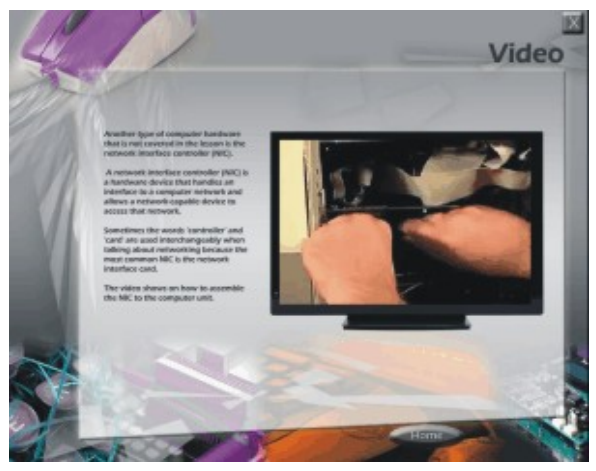

Fig. 9:Video to demonstrate how to assemble network card

\section{RESULTS}

It is proven that courseware is one of the powerful tools that can help student in understanding certain subject. However, the benefits of such systems can only be ensured if it is able to actually transfer the knowledge to the learner (Hammami, 2010). Therefore, summative evaluation takes place at the end stage of
Table 1: Analysis on the Content in the iC-COM

\begin{tabular}{lll}
\hline Item Questions & Mean & S.D \\
\hline The content was reliable. & 3.43 & 0.78 \\
The grammar use is correct & 3.75 & 0.81 \\
Current and error free information & 3.53 & 0.64 \\
Information of sufficient & 3.25 & 0.87 \\
$\begin{array}{l}\text { scope and depth } \\
\text { The content is structured }\end{array}$ & 3.35 & 0.92 \\
$\begin{array}{l}\text { in a clear and understandable } \\
\text { manner }\end{array}$ & & \\
The content is presented in creative way & 4.13 & 0.72 \\
\hline
\end{tabular}

Table 2: Analysis of the Interactivity of the iC-COM

\begin{tabular}{lll}
\hline Item Questions & Mean & S.D \\
\hline $\begin{array}{l}\text { This multimedia courseware } \\
\text { provides opportunities for }\end{array}$ & 3.60 & 1.03 \\
$\begin{array}{l}\text { interaction with standardized icons } \\
\begin{array}{l}\text { This multimedia courseware allows } \\
\text { learners to discover information } \\
\text { through active exploration }\end{array}\end{array}$ & 3.55 & 0.85 \\
\hline
\end{tabular}

Table 3: Analysis on the Navigation of iC-COM

\begin{tabular}{lll}
\hline Item Questions & Mean & S.D \\
\hline Menu key to return to the main page & 4.10 & 0.63 \\
Exit key to exit from the programme & 3.80 & 0.99 \\
Key for moving forward or backward in a lesson & 4.08 & 0.73 \\
Key for accessing the next lesson in a sequence & 4.00 & 0.78 \\
\hline
\end{tabular}

this courseware development. There are 50 students participated in this evaluation process. The study was not concerned about improvements in students' performance before and after using the courseware, no control or experimental group was assigned. Overall, the computer-based learning session took about two hours and later a set of questionnaire was distributed.

Part I of the questionnaire was related to the content of iC-COM which consisted of 6 items. Part II was related to the interactivity which consisted of 2 items. There were 4 items in Part III of the questionnaire that was related to navigation. Part IV of the questionnaire was related to the screen design of $\mathrm{iC}-\mathrm{COM}$ and consisted of 18 items. Table 1 shows the analysis on the content in the iC-COM.

Table 1 show that the mean ranged from 3.25 to 4.13. Item 4 possessed the highest mean value whereas the mean value for item number 3.25, the lowest among the items. Table 2 shows the analysis of the interactivity of the iC-COM. Based on Table 2, the mean ranged from 3.55 to 3.6. Item 7 possessed the highest mean value.

Table 3 shows that the mean ranged from 3.80 to 4.10. Item 9 possessed the highest mean value while the mean value for item number 10 was the lowest at 3.25.

Table 4 shown the mean ranged from to 2.85 to 3.75. Item 20 possessed the highest mean value while the mean value for item number 28 was lowest at 2.85 . 
Am. J. of Economics and Business Administration 3 (1): 132-138, 2011

Table 4: Analysis on the Screen Design of the iC-COM

\begin{tabular}{|c|c|c|}
\hline Item Questions & Mean & S.D \\
\hline Screens designed in a clear and easy to understand & 3.70 & 0.99 \\
\hline $\begin{array}{l}\text { The presentation of information can captivate the } \\
\text { attention of students }\end{array}$ & 3.10 & 1.081 \\
\hline The presentation of information can stimulate recall & 13.38 & 0.84 \\
\hline $\begin{array}{l}\text { The use of space is according to the principles of } \\
\text { screen design }\end{array}$ & 3.63 & 0.87 \\
\hline $\begin{array}{l}\text { The proper fonts in terms of style and size } \\
\text { were used }\end{array}$ & 3.45 & 0.93 \\
\hline The use of text follows the principles of readability & 3.53 & 0.96 \\
\hline $\begin{array}{l}\text { The color of the text follows the principles } \\
\text { of readability }\end{array}$ & 3.63 & 0.90 \\
\hline $\begin{array}{l}\text { The number of colors in each screen is not } \\
\text { more than } 6 \text { colors }\end{array}$ & 3.75 & 0.95 \\
\hline The use of color is consistent & 3.60 & 0.93 \\
\hline $\begin{array}{l}\text { The quality of the text, images, graphics } \\
\text { and video is very good }\end{array}$ & 3.10 & 1.13 \\
\hline $\begin{array}{l}\text { Images uses are relevant to the information } \\
\text { included in the text }\end{array}$ & 3.55 & 1.01 \\
\hline $\begin{array}{l}\text { The use of graphics meaningfully supports the } \\
\text { text provided }\end{array}$ & 3.33 & 1.12 \\
\hline $\begin{array}{l}\text { There is high contrast between graphics } \\
\text { and background }\end{array}$ & 3.48 & 0.88 \\
\hline $\begin{array}{l}\text { The video enhances the presentation } \\
\text { of information }\end{array}$ & 3.35 & 1.10 \\
\hline $\begin{array}{l}\text { The sound is of good quality and enhances } \\
\text { the presentation of information }\end{array}$ & 3.33 & 1.16 \\
\hline $\begin{array}{l}\text { The sound is an alternative means of } \\
\text { presenting information and not a necessity }\end{array}$ & 2.85 & 1.19 \\
\hline $\begin{array}{l}\text { The integration of presentation means is } \\
\text { well coordinated }\end{array}$ & 3.70 & 0.76 \\
\hline
\end{tabular}

\section{DISCUSSION}

Courseware evaluation has been around as long as courseware, but with the spread of microcomputers and relatively inexpensive commercial programs in the early 1980s, it became necessary for large numbers of classroom teachers to learn how to evaluate courseware themselves. Therefore, an instructional system design model which consists of phases that include evaluation phase was chose. ADDIE instructional system design consisted of five phases: Analysis, Design, Development, Implementation and Evaluation. This model provided the means to identify the needs of target audience's to be used for the courseware design and development. The last phase was the evaluation phase that was essential to ensure that the needs of the students being met. There were many other researchers (Mahmud et al., 2009; Asmawi and Abdul Razak, 2006; Aris et al., 2006) that used the ADDIE model to develop an interactive courseware.

The evaluation analysis of iC-COM content proof that the users agree the content is reliable and structured in a clear way. The result of item 6 that attracted researcher's attention is in terms of the content that presented in creative way which possessed the highest mean range. The analysis of the interactivity shown that
iC-COM provides opportunities for interaction with standardized icon and allow learners to discover information through active exploration. The last part of the questionnaire is the analysis of the screen design. This part consists of the questions that cover the consideration of text, graphics, audio and video. It can be conclude that for the use of text, graphics and audio in $\mathrm{iC}-\mathrm{COM}$ are presented in a way that helpful to the user. While the audio question possessed lower mean score which is 2.85 . The user seems not agree that the sound is an alternative means of presenting information and not a necessity. Based on this analysis, it is recommended that the sound is a necessity in iC-COM and user will be provided with the features that can switch off and on the audio whenever they need.

For future enhancement, it is recommended that iC-COM will be integrated into web-based platform so it can be accessed easily anywhere. Web service technology has emerged as a new paradigm of distributed computing (Mohammed and Hussein, 2010). In addition, the courseware must be equip with quiz and test part to measure user understanding. There must be also database to save user information so that all the marks gain from the test can be stored.

\section{CONCLUSION}

The emergence of e-learning has led to a proliferation of platforms whose purpose is to group a set of features to support the needs of the training (Belkasmi et al., 2010). The courseware product, if employed as the lecture source, can make the classroom lectures more informative and, at the same time, more exciting by enhancing student participation in classroom discussions. The intention is to have a more active learning environment rather than a passive one. Such enhanced participation by students should result in higher learning curves. A dynamic learning atmosphere can potentially be produced due to the multimedia nature of the courseware package-short video scenes, scanned pictures and its connection to other software packages.

The different topics of iC-COM has been developed in a brief and precise way with the objective of emphasizing the most important part of learning basic computer system components involved in the detail of characteristics of every computer components. Finally, iC-COM can be an alternative way to improve $\mathrm{T}$ and $\mathrm{L}$ process and maybe considered as a contribution to improve conventional teaching method.

\section{REFERENCES}

Aris, B., M.H. Ahamd, K.B. Shiong, M.B. Ali and J. Harun et al., 2006. Goal programming” using an interactive multimedia courseware: design factors and students' preferences. Malaysian Online J. Instruc. Technol., 3: 85-95. 
Asmawi, A. and R.A. Razak, 2006. The instructional design evaluation of a courseware of a Malaysian Virtual University. Malaysian Online J. Instruc. Technol., 3: 1-10.

Belanger, F. and D.H. Jordan, 2000. Evaluation and Implementation of Distance Learning: Technologies, Tools and Techniques. 1st Edn., Idea Group, ISBN: 1878289632, pp: 246.

Belkasmi, M.G., T. Bouchentouf, M. Azizi and A. Benazzi, 2010. Modeling projects in e-learning course: a case of an information technology project. J. Comput. Sci., 6: 823-829. DOI: 10.3844/jcssp.2010.823.829

Delombaerde, F., C.A. Madramootoo and B. Mehdi, 2001. Development of a hydrology multimedia courseware. Canadian Biosyst. Eng., 43: 23-30. Hammami, S., 2010. evaluating e-learning systems using e-traceability systems. J. Comput. Sci., 6: 210-216. DOI: 10.3844 jcssp.2010.210.216

Helm-Stevens. R. and O. Griego, 2009. Evaluating experiential learning in organizational behavior: taking measure of student perception regarding group experience. Am. J. Econ. Bus. Adminis., 1: 138-140. DOI:10.3844/ajebasp.2009.138.140

Hodell, C., 2006. ISD from the Ground Up: A NoNonsense Approach to Instructional Design. 2nd Edn., ASTD Press, USA., ISBN: 1562864556, pp: 200.

Inglis, A., V. Joosten and P. Ling, 2002. Delivering Digitally: Managing the Transition to the Knowledge Media. 2nd Edn., Routledge Publisher, London, ISBN: 0749434716, pp:192.

Iskandarani, M.Z., 2008. Effect of Information and Communication Technologies (ICT) on nonindustrial countries-digital divide model. J. Comput. Sci., 4: 315-319. DOI: 10.3844/jcssp.2008.315.319
Kuppusamy, M., M. Pahlavani and A.S. Saleh, 2008. Fostering ICT development for growth: Measuring the payoffs for Australia and the Asean-5 countries. Am. J. Applied Sci., 5: 1676-1685. DOI: 10.3844/ajassp.2008.1676.1685

Lynch, M.M. and J. Roecker, 2007. Project Managing E-learning: A Handbook for Successful Design. 1st Edn., Delivery and Management: Routledge Publisher, ISBN: 9780415772204, pp: 208.

Mahmud, R., M.A. Ismail and L.A. Kiaw, 2009. Development and evaluation of a CAI courseware 'G-Reflect' on students' achievement and motivation in learning mathematics. European J. Soc. Sci., 8: 557-568.

Mohamed, S. and A.R. Bakar, 2008. How Prepared are Trainee Teachers of University Putra Malaysia (UPM) to integrate computer technology in classroom teaching? J. Soc. Sci., 4: 62-67. DOI: $10.3844 /$ jssp.2008.62.67

Mohammed, A.J. and H.K.A. Omari, 2010. E-Learning management system using service oriented architecture. J. Comput. Sci., 6: 285-295. DOI: 10.3844/jcssp.2010.285.295

Vaughan, T., 2006. Multimedia: Making it Works. 7th End., McGraw-Hill Professional, UK., ISBN: 9780072264517, pp: 415.

Westwood, P., 2008. What Teachers Need to Know About Teaching Methods. 1st Edn., Acer Press, ISBN: 9780864319128, pp: 105. 